\title{
IMPACT OF THE INTEGRATED FOOD AND NUTRITION PROGRAMME IN KUNGWINI, SOUTH AFRICA
}

\section{Dr Reineth (CE) Prinsloo (Corresponding author)}

Senior Lecturer

Department of Social Work and Criminology, Faculty of Humanities, University of Pretoria, Pretoria, 0002

0124202601 (Office)

0124202093 (Fax number)

reineth.prinsloo@up.ac.za

\section{Dr V Pillay}

DPhil (Social Work) student

13 Mozart Street, Vorna Valley, Midrand, 1686

PO Box 3287, Halfway House, Midrand, 1685

0726649101

vasintipillay.ptl@gmail.com

\section{ABSTRACT}

This article discusses the impact of the Integrated Food and Nutrition Programme (IFNP) in light of collaborative partnerships for poverty reduction in a developing municipal area in South Africa. The programme aimed to develop home, community and school food gardens to meet the daily nutritional needs of poor households and the process was then to be broadened into marketing surplus garden produce, providing employment and income-generating opportunities. The programme thus aimed to address more than just basic food and nutrition. The purpose of the research was to obtain data through participant observation, focus group discussions and extended household interviews. Drawing on the qualitative interviews conducted with the beneficiaries of the IFNP, the article describes the manner in which poverty can continue to entrench the social exclusion of the poor (despite a specific policy intervention to improve their circumstances) when appropriate stakeholder collaboration is not fully developed and harnessed. The research recommendations include improving weak institutional environments, which 
may hinder effective service delivery, identifying appropriate skills development for the poor, ensuring community involvement in policy processes, maintaining efficient communication in collaborative partnerships, and maintaining personnel training on policy development and in project management skills.

Keywords: household food needs; nutrition; policy intervention; poverty reduction; collaborative partnerships.

\section{ABSTRACT}

This article discusses the impact of the Integrated Food and Nutrition Programme (IFNP) in light of collaborative partnerships for poverty reduction in a developing municipal area in South Africa. The programme aimed to develop home, community and school food gardens to meet the daily nutritional needs of poor households and the process was then to be broadened into marketing surplus garden produce, providing employment and income-generating opportunities. The programme thus aimed to address more than just basic food and nutrition. The purpose of the research was to obtain data through participant observation, focus group discussions and extended household interviews. Drawing on the qualitative interviews conducted with the beneficiaries of the IFNP, the article describes the manner in which poverty can continue to entrench the social exclusion of the poor (despite a specific policy intervention to improve their circumstances) when appropriate stakeholder collaboration is not fully developed and harnessed. The research recommendations include improving weak institutional environments, which may hinder effective service delivery, identifying appropriate skills development for the poor, ensuring community involvement in policy processes, maintaining efficient communication in collaborative partnerships, and maintaining personnel training on policy development and in project management skills.

Keywords: household food needs; nutrition; policy intervention; poverty reduction; collaborative partnerships. 


\section{Introduction}

Poverty is prevalent in South Africa in both rural and urban areas, where both absolute and extreme poverty are widespread. The terms of absolute, relative and extreme poverty are often used interchangeably (Notten \& De Neubourg 2011). Absolute and extreme poverty are defined as a deprivation of food, safe drinking water, shelter, sanitation facilities, health care, and education and involves living on less than USD1 per day, regarded as the international poverty standard measure (Effah, 2006; Ferrante, 2010; Tregenna, 2012). Sub-Saharan Africa needs the eradication of extreme poverty and hunger for inclusive development (Effah, 2006). Poor communities in South Africa, included in the Sub-Saharan region, experience many problems, including a lack of basic amenities such as clean water, adequate sanitation, and affordable energy sources. The high rate of unemployment amongst the poor exacerbates their plight (Webb, 2011). Various programmes endeavour to alleviate poverty in South Africa, with varying success, as not all programmes address poverty effectively (Groenewald, 2011; Naidoo, 2011). Food security through agricultural programmes and development play a key role in lessening poverty by steering economic growth and hunger in developing countries (McLachlan and Hamann, 2011; Shisanya and Hendriks, 2011).

\section{Purpose of the Integrated Food and Nutrition Programme}

It is against the information provided above that this qualitative research study explored the impact of the Integrated Food and Nutrition Programme (IFNP) in a local municipality in South Africa. The IFNP was a joint effort between the National Department of Social Development and the Gauteng Provincial Department of Social Development. The programme aimed to develop home, community and school food gardens to meet the daily nutritional needs of poor households. The aim of the programme was to broaden the process into marketing surplus garden produce, providing employment and incomegenerating opportunities. The IFNP was to be implemented in partnership with the Departments of Health, Education, and Agriculture, and with community organisations. 


\section{Background}

The National and Provincial Departments of Social Development originally established the IFNP to address poverty. The first and overarching Millennium Development Goal (MDG) adopted at the United Nations Millennium Summit in New York in 2000 calls for the eradication of extreme poverty (Groenewald, 2011; Tregenna, 2012). The IFNP therefore included the MDG focus of reducing world hunger, malnutrition and food insecurity by half by 2015 . To this end, the IFNP's goal was to increase household food and income to assist poor households in communities to attain a better standard of living.

During 1994, the poor in South Africa received a glimmer of hope, when the government expressed its commitment to address poverty through the Reconstruction and Development Programme (RDP). The RDP acknowledged the need for integrated planning involving various departments responsible for the provision of housing, education, welfare, water and sanitation, health, land and agricultural reform, and the supply of electricity (Gray, 2006). Although the programme created optimism, it could not address the national backlog in housing. In addition, there were inadequate resources to address the various needs of the poor.

The RDP ended with the establishment of the Growth, Employment and Redistribution (GEAR) programme (Mubangizi, 2008). During 1996, government refocused its poverty relief efforts by shifting its focus to the economic growth of South Africa, through the GEAR programme (Singh, 2010). The rationale that underpinned this approach was the argument that an improved economy would allow benefits to filter down to the poor (Streak, 2004). However, GEAR failed to meet the expectations of government, and other pressing problems urgently had to be addressed in South Africa, apart from poverty (Singh, 2010), including the HIV/AIDS pandemic and spiralling crime.

Subsequently, the Accelerated Shared Growth Initiative for South Africa (ASGISA) replaced GEAR. The intention was to enable the informal sector, especially women, to participate in formal economic processes in South Africa 
(IDASA, 2006). ASGISA has also not fully achieved its mandate to address poverty in South Africa to a measurable extent (Mubangizi, 2008). Although many programmes were developed and implemented, the situation facing the poor remains grim. South Africa introduced the Child Support Grant (CSG) in 1998 as a way to assist children and their caregivers within a developmental social context (Vorster and De Waal, 2008; Makiwane, 2010). In spite of the fact that the social security system include more beneficiaries every year and the age of children eligible to receive the CSG was increased, poverty has not been reduced (Holborn and Eddy, 2011). Versi (2014) reiterates that poverty in the continent of Africa has not lowered and Altman, Mokomane and Wright (2014) confirm that poverty in South Africa is extensive, especially amongst the youth who do not qualify for any social assistance.

\section{Research setting}

The residents of the geographical research area chosen for this study experience large-scale development in the central business centre. Many poor households however do not benefit from this local economic growth and remain in poverty. Poverty in the area can be broadly defined as a decline in household assets and household incomes to the point where household income cannot adequately meet a family's physical and material needs (Mubangizi and Mubangizi, 2005; Oldewage-Theron and Slabbert, 2008; Ferrante, 2010).

The population for this study were beneficiaries of the IFNP from poor households, living with extended family members. Most of the roads in the area are dirt tracks. Electricity, water and sewage removal are provided to formal households, but not to dwellings in the informal settlements where households share communal street taps. Where there are no communal taps, residents purchase water from householders in the formal settlement.

\section{Research question}

The research question for the study was 'What is the impact of the IFNP on the poor in Kungwini?' An empirical investigation, using focus groups and extended 
household interviews in a qualitative research approach provided answers to the research question. The focus group discussions and extended household interviews were conducted with IFNP beneficiaries, who provided rich sources of information regarding the impact of the programme in terms of poverty reduction in the area. Participant observation supplemented the interviews.

\section{Aims and method}

The aims of this research study were to explore the impact of the IFNP in the specific area to determine whether the programme has contributed to a reduction in poverty, and to provide recommendations to policy-makers at national and provincial levels in order to assist in transforming service delivery to the poor.

A qualitative research design was chosen to explore the impact of the IFNP on beneficiaries in Kungwini; the objective was to explore their personal views on the level of improvement in their living conditions (Naidoo, 2011). The voices of the poor are significant additions to supplement quantitative studies on poverty (Okech et al, 2012). Participants for the focus group discussions and the extended household interviews were purposively selected beneficiaries of the IFNP. There were six focus group interviews, with ten respondents in each group. The four extended household interviews were conducted with households comprised of unemployed parents, grandparents living with the family, and school-going children.

The qualitative focus group interviews involved questions based on the IFNP Strategic Plan, which is the policy framework for the IFNP, and participant observation, focusing on lived experiences of the participants, to establish common themes (Creswell, 2009; Greeff, 2011). The interview schedule included the following questions, based on the objectives of the IFNP:

- How were you assisted to improve your household food needs?

- How were you assisted to establish food gardens?

- How were you assisted with skills development?

- How were you assisted to access child or pension grants? 
- How were you assisted to form community organisations?

\section{Research findings}

An overview of the responses from the focus group and extended household interviews follow below, grouped according to the main themes that emerged.

\section{The contribution of food parcels}

The IFNP's Strategic Plan included ensuring adequate household nutrition by means of food packages, especially for households with children, the elderly and the disabled, with special food needs. The food packages were to take the form of a food basket customised for the composition of specific households and was the responsibility of the Department of Health. The Department of Agriculture was to assist poor households to establish food gardens to supplement these households' daily food needs. However, from the focus group discussions, it became clear that the focus group members were not aware of the above objectives of the IFNP.

A recurring theme in the focus group discussions and the extended household interviews was that the food parcels helped, but were not adequate. This confirms the necessity of sound management skills to achieve and ensure an integrated approach to increasing household food production in a project such as the INFP (Boyle, 2003; Rahaman and Varis, 2005). In the absence of a collaborative team effort, the aim to ensure adequate food to poor households was not attained. Participants responded 'The food parcels were okay, but we need a better place for growing vegetables. There is not enough vegetables for selling.' "The food parcels helped my family. My husband works repairing cars, but is not paid regularly, as the people do not always have money. There are six adults and 12 children, including seven grandchildren, and two foster children, who are not getting the grant.' 
Some of the children responded that 'The food parcel was not enough. We do not have enough food'; 'It was a difficult time for us when my father died. The food parcels helped us' and 'We still need more food to help us.'

\section{Assistance to establish food gardens}

Overall, participants indicated that they were not assisted to meet their household food needs through the establishment of food gardens. Again, lack of coordinated intervention and fragmented service provision was apparent in the distribution of tools and training to establish food gardens. In response to the question of whether a household food garden would assist them to supplement their daily food needs, participants answered in the affirmative. The focus groups' feedback suggested that they were not very keen on establishing household food gardens, as they related how difficult crop production from poor soil in limited garden spaces is, and they commented on the long wait between planting and harvesting.

The extended household visits and observation provided visual data in relation to the question on the food gardens, and gave a clearer indication of the situation on the ground than the focus groups' sometimes-vague responses. Observation revealed that the beneficiaries' garden spaces were merely barren baked earth, which would require hard manual labour to improve the soil in order to establish household food gardens.

One house was an exception - the householder had extended his vegetable garden onto a patch of vacant land and was operating as a small-scale farmer. $\mathrm{He}$ received training from the Department of Agriculture and continued to implement the knowledge. This initiative was not operating on high profit margins, but helped his family to meet its food needs and brought in some income, as they sold surplus crops to neighbours.

Gardening difficulties experienced by the beneficiaries included limited water resources, inadequate gardening spaces, and inadequate returns for daily household provisions. These findings are in line with the caution in the literature 
that many poverty policies and strategies neglect the realities of agricultural production and markets (Webb, 2011). The implication of the results reported from the research setting is that the IFNP did not achieve its objective to establish household and community food gardens in Kungwini, or to develop employment opportunities through economic initiatives based on vegetable gardens.

As agriculture remains a key policy strategy to reduce poverty (Dorosh and Mellor, 2013), it is important to address arid soil conditions, pestilence, crop diseases, and the effects of climate change through effective management (Adam, 2008; O'Riordan et al, 2008). If skilled assistance fails to deal with these problems effectively, subsistence farming leads to food insecurity (Webb, 2011). The research results illustrate the need for interdepartmental collaboration to sustain poverty programmes.

Appropriate agricultural training and relevant assistance from applicable sources are crucial to enable small scale farming initiatives to yield viable crop production (Dorosh and Mellor, 2013). According to the participants of the research study, the training and resources provided appear to have been inadequate overall, although one flourishing garden made a visible difference in Kungwini, which indicates the willingness of some poor households to learn and apply new skills. Some of the responses illustrate the dilemma. 'I received a hose-pipe. But I need training to start the vegetable garden. I could not continue with the vegetable garden, as I ran out of seeds. I did not collect the seeds. Was I supposed to?' Another participant gave a similar response: 'I received the fork, the hosepipe, and the spade, but no seeds. I still have the tools. I did not use them. We did not receive any assistance to develop a food garden ... we did not receive any training.'

\section{Assistance with skills development}

The question of assistance with skills development elicited more lively discussion in all the focus groups than the previous questions. Participants were, without exception, eager to acquire new skills for employment or to begin 
their own business enterprises. This issue was of paramount importance to them. It appeared to surpass the need for adequate food. It emerged that they required more skills than limited agricultural training to develop food gardens. Group members commented that they '... are struggling, we are poor; we are not educated, and we need skills to get jobs.' The need for training was expressed in the following excerpt: 'No, we did not receive any training. I would like to develop a business where I could earn more money, as I am working part-time as a domestic.'

The question did not provoke equally lively discussions in the extended household discussions. Given the poverty-stricken conditions of the extended households, it became clear that skills training in this context was almost irrelevant. Skills training and these households' immediate need for adequate food and a better quality of life could not be reconciled. The adolescents and young adult females in the households appeared to be hesitant in their responses, although they indicated that they thought skills training was a good idea. There were many young children in three of the extended households. It appeared as if skills training would require further effort, in addition to dealing with the daily care of the family, with the associated burdens of poverty.

The question remains why the IFNP was unable to address the socio-economic needs of poor households. The answer may lie in the relation between the IFNP and the GEAR programme, which attempted to assist the poor to improve their socio-economic circumstances. GEAR has failed to address the serious lack of socio-economic development in poor communities, as there has been no largescale improvement in the general South African economy (Mubangizi, 2008; Singh, 2010; Finn et al, 2014).

The gap between the informal and the formal sectors in Kungwini is so wide that it may be impossible to close the chasm between the two sectors. Even with social security, the poor may not be able to overcome socio-economic social barriers without considerable assistance from related spheres of government. Radical intervention strategies aligned to human and financial resources are 
required to assist poor households to overcome their adverse circumstances (Adato et al, 2006; Chen, 2005).

\section{Social security}

Social security ensures that impoverished families are able to rear their children (Holborn and Eddy, 2011; Vorster and De Waal, 2008). This may enable children to complete their schooling and to steer away from negative social circumstances that have a detrimental effect (Goldson, 2002; Kalil and ZiolGuest, 2008). Neglected children, especially those from poor households, may remain deprived for most of their adolescent and adult years. The IFNP's objective to steer poor households in Kungwini to appropriate social security programmes was a positive strategy goal in view of the fact that children from poor households often experience gross neglect in terms of their emotional and physical needs (Holborn and Eddy, 2011). Adverse circumstances lead to personal distress and aggressive behaviour in children, as the family environment influences a child's emotional well-being (Daniel and Taylor, 2006; Goodvin et al, 2006).

The implications of neglect for children living in poverty-stricken conditions are severe. The IFNP did not follow through on its objective to align the project with the social security programme in Kungwini. The children who participated in the extended household interviews indicated that they were always hungry. Children from poor households tend to experience chronic and severe malnutrition, leading to calcium, iron and zinc deficiencies. Owing to poor home circumstances, which may include high unemployment levels, dealing with the HIV and AIDS pandemic, and a lack of adequate nutrition, their physical and mental health may be compromised, as described by Featherstone (2006), Gakidou et al (2007) and Pharaoh (2005). This, in turn, affects early childhood development and school education.

Low and irregular household income mark the unemployment situation in Kungwini, apart from those homes that receive a child support grant and/or an old age pension. The old age pension meets part of the daily food needs in 
some poor homes, but unemployed family members living with the elderly lead to severe poverty. One group member commented 'I receive the old age grant and the younger ones in the family receive the child support grant. My wife has a disability and we would like to apply for a disability grant. We need help.'

From the focus group discussions and the extended household interviews, the resilience of the poor when faced with adversity was apparent, especially among some of the women, who undertook low-paid work to feed their children and families, whether or not the family received a child support grant and/or old age pension. They were prepared to receive skills training to improve their circumstances. The IFNP, in collaboration with other initiatives, should have tapped this source of community strength to reinforce its objectives to improve the socio-economic situation, which would then be in line with the MDG to reduce poverty.

Responses from the focus group and extended household participants were similar, in that they reported that an old age pension and a child support grant assisted their families to provide household food and to pay for medical emergencies, lights and water. However, it was apparent that the social grants did not meet all the needs of poor households. The following responses highlight the problems: 'Since my mother passed away, the grant has been cut. Her grant helped the family to buy food. We need assistance now.' The contribution of the support grant is clear from the following: 'My two young children receive the child support grant. My 16-year old does not. I am now a single parent, as my husband died. The child support grant is the only income.'

By 31 October 2013, 15,240,126 South Africans received social grants (A statistical summary of social grants in South Africa. Fact sheet: Issue no 10 of 2013), yet millions are still peer and need assistance. Although grants assist with daily living expenses, food bought with grant money is often inadequate for large extended families. Some of the participants expressed unhappiness with the difficulties in accessing grants where applications were unsuccessful. Responses from participants convey the following: 'I take care of 13 children, including seven of my own, four grandchildren and two foster children aged four 
and five. Only my husband works when he can get work. I receive the disability grant. Three of the children receive the child support grant, but not the two foster children, because of their birth certificates. Their mother, who is my niece, is mentally ill and has no ID. We applied a year ago for the ID at Home Affairs. Five years ago we applied for the one foster child's birth certificate. One came back, but they put in male instead of female. We are still waiting for the two birth certificates.'

A lack of birth certificates and identification documents, especially in rural areas, prevent the poor from accessing social grants (Vorster and De Waal, 2008). Research responses indicated a lack of understanding regarding the various grant processes, reflecting upon the need for collaborated efforts amongst poverty alleviation initiatives. The child support and pension grants take the edge off poverty in many poor households in South Africa (Gray, 2006; Vorster and De Waal, 2008) but do not meet the total needs of poor households. Relevant poverty policies, based upon collaborative efforts should address socio-economic needs, and secure social justice for women and children, which further strengthens families to take adequate care of family members, despite the limitations of poverty (Okech et al, 2012).

\section{Assistance in forming community organisations}

Creating community food gardens to address food insecurity requires an understanding of the nature of the problem and appropriate coordinated measures to address various types of poverty (Dorosh and Mellor, 2013; McEvan, 2005). It is important to distinguish between the chronic poor (those likely to remain in poverty) and the transitory poor, in order to maximise valuable resources, including those provided by the IFNP (Notten and De Neubourg, 2011). It is imperative to gather relevant facts and information regarding the specific targets for intended services before establishing community organisations to assist poor households.

Participants in the focus groups and household interviews were asked how they were assisted to form community organisations. From the responses, it was 
clear that the above guidelines were not followed prior to establishing the IFNP. The IFNP did not use specific criteria to identify elderly and female-headed households that represent the diverse categories of the chronic poor. A blanket decision was taken to distribute food packages to random households visited by local councillors, which implies diverse interest group agendas in policy processes and programme implementation (Ball and Peters, 2005). Because of improper targeting, the IFNP's primary objective of addressing poverty effectively was compromised.

In order to establish community organisations to ensure food security, it is imperative that crucial issues affecting the poor are addressed through a collaborative effort by various government departments (Webb, 2011). This includes creating a suitable environment for economic development, improving social and health services, and ensuring social protection for vulnerable groups (Mubangizi, 20018). The various strengths of community members in Kungwini should have been harnessed to reduce poverty (Okech et al, 2012).

The participants' non-verbal cues appeared to register a sense of hesitancy regarding food security through the establishment of community organisations. The vulnerable circumstances of the poor should be addressed in a sensitive manner to ensure that they are not exposed to further vulnerability (Sacks, 2008). In this case, it was imperative to enlist their cooperation to reduce their vulnerability. Creating a positive environment that included a flexible approach to dealing with the poverty situation would have been more constructive in achieving the IFNP's objectives than the adopted top-down approach, marked by a lack of coordination, and the non-sustainability of the programme (KayizziMugerwa, 2003).

Community-based networks, based upon thorough and collaborative assessments empower the poor and include community-driven enterprises to improve service delivery, based on grassroots experiences and skills (Boyle, 2003; Spira and Wall, 2006). The rights of vulnerable groups to freedom from hunger and economic development remain crucial issues in establishing various community organisations (Wolf-Powers, 2008). A partnership between 
government and civil society in Kungwini is essential to address extreme poverty and hunger. The lack of consultation is clear from the responses. 'We did not know. With the right training, we can have many businesses.' The following response comments on the lack of information. 'I do not know about this. As I am a farmer, I can see that we will need a big place. For me, I need to have a big place to start other businesses, also for a bigger house and office space.'

\section{Discussion}

The responses from the focus group and extended household interviews indicate that the IFNP did not have a measurable impact in reducing poverty in Kungwini. A number of crucial factors adversely affected the achievement of the IFNP's objective to address poverty effectively, including a lack of interdepartmental and civil society collaboration and programme sustainability. Webb (2011) emphasises that urban agricultural programmes should not be deemed successful without proper collaboration and grounded analysis through research. Coordinated programmes should support people involved in economically sustainable agricultural projects to increase household incomes (Shisanya and Hendriks, 2011; Tregenna, 2012). Many factors, as seen in the participant responses, play a role in the success or failure of such programmes.

The authors strongly agree with Mubangizi (2008:179) that 'the inability to include beneficiaries in the planning and implementation of poverty alleviation strategies fails to deal with poverty from a structural point of view'. The goal of poverty alleviation interventions should be to include the poor as contributors right from the onset of planning the programmes.

The primary focus of the IFNP was agricultural development through household and community food gardens, which would then expand to marketing agricultural produce. This aspect closely aligns to employment creation. However, creating or obtaining employment remains a serious problem for the majority of the poor, who continue to struggle for their daily living through unskilled labour, when this is available. In order to bridge the gap between the 
poor and the wealthy in terms of human development and the economy, there is a need to fast-track socio-economic development, including agricultural initiatives. The question remains whether agricultural initiatives will address poverty adequately, as the participants in this research study indicated their need for specific training, rather than a focus on developing household and community food gardens to provide for their family's needs. Support through suitable skills training programmes in aspects such as marketing, enterprise development and crafts instruction could be included into public works programmes (Mubangizi, 2008). Accommodating local government policies of enterprise opportunities for beneficiaries could assist in sustainability of initiatives.

Anti-poverty programmes should include a range of related projects to achieve concrete outcomes, based on specific targeting, effective monitoring and evaluation. A well-planned and executed poverty programme is more likely to ensure policy success. However, public poverty programmes in many instances operate independently and, in the process, services to the poor are duplicated. Poverty should be seen as a multi-dimensional problem that requires integrated multi-sectoral intervention (Mubangizi and Mubangizi, 2005; Okech et al, 2012). This was clearly a crucial factor in the lack of success of the programme. Sound management skills assist in the achievement of policy objectives, through effective planning and goal setting. Effective administration supports a public environment that promotes and provides optimum service standards. Policy development processes should include continuous policy evaluation to determine whether a programme has achieved its stated goals and reached its intended target.

Programmes should not be terminated without assessing whether the problem has been effectively addressed. The IFNP was terminated without ensuring that the programme was linked to existing poverty programmes. Hence, a crucial question remains at what point policy-makers decided that the needs of poor households in Kungwini had been met. 
Government's commitment to the poor should be translated into effective policy management by those entrusted with bringing change to millions of poor in South Africa (Mubangizi and Mubangizi, 2005). The research findings paint a gloomy picture, which illustrates the right motives in establishing a food and nutrition programme. However, the programme was based on an unstable foundation without considering the low economic growth in South Africa and the difficulties that the poor experience in accessing capital funding to establish their own businesses. The key factor for policy efficiency continues to be collaboration and programme sustainability, backed by alternative policy solutions in case a current programme fails to achieve its objectives.

\section{Recommendations}

Improving the circumstances of the poor requires a thorough assessment of the difficulties they experience. Different stakeholders focusing on the multidimensional needs of the target group should do such an assessment. This includes identifying appropriate skills training for the job market and/or developing small business enterprises.

Participating beneficiaries of poverty reduction programmes focusing on agricultural activities for food and nutrition should receive agricultural and nutritional advice to improve the quality and quantity of production and to encourage the participation of those involved (Shisanya and Hendriks, 2011). African countries should provide support for agriculture, education and health care to aid in development and reducing poverty (Effah, 2006). The research results confirm that the lack of such advice and support can have an influence on the successful output of a programme such as the IFNP.

Community involvement in policy development and policy implementation processes will address fragmented service delivery, which has a detrimental effect upon the poor. This includes establishing and maintaining efficient and coordinated communication between departments, community organizations, and key stakeholders. Mubangizi (2008) emphasises that social workers and practitioners involved in community development should play an active role to 
enhance people's political consciousness and resilience. They should support self-reliance initiatives at community level and promote supportive policy and institutional support to increase capacity to achieve this.

Personnel training should include policy and practical project management skills to ensure transparency and cost-effective service delivery. Addressing policy constraints through alternative policy options will ensure that programmes are on track to achieve policy goals and objectives. Establishing efficient monitoring and evaluating systems will keep track of programme implementation constraints. Coordinated efforts to align poverty programmes to service delivery initiatives ensure maximum impact to reduce poverty.

Policy development depends on knowledge about the nature of longer-term well-being through coordinated assessments by multi-professional stakeholders who design interventions to address poverty effectively (Finn et al, 2014). Identifying and dealing with weak institutional structures that hinder effective service delivery optimises valuable resources. Maintaining stakeholder participation is imperative for policy success. A collaborative partnership includes the expertise of relevant stakeholders and community dynamism to guide policy processes. Hard work, leadership and unity in planned initiatives can assist in reducing poverty.

\section{Conclusion}

The initial objective of the programme to reduce poverty through food and nutrition initiatives is commendable. Many people in rural areas in developing countries are directly or indirectly busy with agricultural activities. Agriculture could thus be a valuable way to reduce poverty and food insecurity (Machethe, 2004). Farming on a small scale, combined with appropriate agricultural production technologies can ensure food security in rural areas (Shisanya and Hendriks, 2011). However, the research results confirm that a number of crucial factors limited the achievement of the IFNP's objective to address poverty. These included a lack of collaboration and of programme sustainability. The primary focus of the IFNP was agricultural development through household and 
community food gardens, which were then supposed to expand to include various socio-economic activities. There was a need, however, for appropriate skills training to obtain employment, which was unrelated to household or community gardens.

Effective communication strategies should be in place to provide information regarding the goal and objectives of a specific programme and to enable networking between relevant departments and organisations. The conclusions from the qualitative data indicate that the IFNP required interactive collaboration to achieve the programme's policy objective of reducing poverty in the area.

This paper calls for action to collaborate towards coordinated interventions to address the problem of poverty in South Africa. These collaborate partnerships should include communities whose residents suffer the dire consequences of poverty. Within the partnerships, the voices of the poor may be the most important contribution towards policy development.

\section{REFERENCES}

Adam, B. (2008) 'Future matters: futures known, created and minded', TwentyFirst Century Society, 3(2): 145-57.

Adato, M., Carter, M.R. and May, J. (2006) 'Exploring poverty traps and social exclusion in South Africa using qualitative and quantitative data', Journal of Development Studies, 42(2): 226-44.

Altman, M., Mokomane, Z. and Wright, G. (2014) 'Social security for young people amidst high poverty and unemployment: Some policy options for South Africa', Development Southern Africa, 31(2): 347-362.

A statistical summary of social grants in South Africa Fact sheet: Issue no 10 of 2013 - 31 October 2013. (2013) www.sassa.gov.za 
Ball, A.R. and Peters, B.G. (2005) Modern Politics and Government, $7^{\text {th }}$ ed. Palgrave MacMillan: New York.

Boyle, A. (2003) Community Nutrition in Action: an Entrepreneurial Approach, $3^{\text {rd }}$ ed. Belmont, California: Wadsworth/Thomson Learning.

Chen, M.A. (2005) Rethinking the informal economy linkages with the formal economy and the formal regulatory environment, New Delhi: Sage.

Creswell, J.W. (2009) Research design: qualitative, quantitative and mixed methods approaches, Sage, London.

Daniel, B.M. and Taylor, J. (2006) 'Gender and child neglect' Critical Social Policy, 26(2): 426-30.

Dorosh, P.A. and Mellor, J.W. (2013) 'Why agriculture remains a viable means of poverty reduction in Sub-Saharan Africa: the case of Ethiopia', Development Policy Review, 31(4):419-441.

Effah, K.B. (2006) 'Human factor dynamics of minimizing extreme poverty and hunger in Africa', Review of Human Factor Studies, 12(1): 65-95.

Featherstone, B. (2006) 'Why gender matters in child welfare and protection', Critical Social Policy, 26(2): 294-14.

Ferrante, J. (2010) 'Global inequality and the challenges of reducing extreme poverty', Sociological Viewpoints, 26(2): 73-83.

Finn, A., Leibbrandt, M. and Levinsohn, J. (2014) 'Income mobility in a highinequality society: Evidence from the first two waves of the National Income Dynamics Study', Development Southern Africa, 31(1): 16-30.

Gakidou, E., Oza, S., Vidal Fuertes, C., Li, A.Y., Lee, D.K., Sousa, A., Hogan, M.C., Vander Hoorn, S. and Ezzati, M. (2007) 'Improving child survival through 
environmental and nutritional interventions. The importance of targeting interventions towards the poor', Journal of the American Medical Association, 298(16 Oct): 1876-87.

Ghai, D. (2000) Renewing Social and Economic Progress in Africa, New York: St Martin's Press.

Goldson, B. (2002) 'Children in need' or 'Young offenders?' Hardening ideology, organizational change and new challenges for social work with children' Child and Family Social Work, 5(3): 255-65.

Goodvin, R., Gustavo, C. and Torquati, J. (2006) 'The role of child emotional responsiveness and material negative emotion expression in children's coping strategy use' Social Development, 15(4): 591-609.

Gray, M. (2006) 'The progress of social development in South Africa', International Journal of Social Welfare, 15(Suppl. 1): S53-S64.

Greeff, M. (2011) Information collection: interviewing. In De Vos, A.S. (Ed.), Strydom, H., Fouché, C.B. \& Delport, C.S.L. Research at grass roots: For the social sciences and human service professions, $4^{\text {th }}$ ed. Pretoria: Van Schaik Publishers.

Groenewald, L. (2011) 'Progress towards Millennium Development Goals? Strategies for housing and informal settlement in Gauteng, South Africa', Development Southern Africa, 28(50): 641-51.

Holborn, L. and Eddy, G. (2011) First steps to healing the South African family. A research paper by the South African Institute of Race Relations sponsored by the Donaldson Trust, Johannesburg: South African Institute of Race Relations.

IDASA (Institute for Democracy in South Africa) (2006) Annual Report. Budgetary perspectives on shared growth policy interventions in South Africa. http://www.idasa.org.za 
Kalil, A. and Ziol-Guest, K.M. (2008) 'Parental employment circumstances and children's academic progress', Social Science Research, 37(20): 500-515.

Kayizzi-Mugerwa, S. (2003) Reforming Africa's institutions. Ownership, incentives and capabilities, New York: United Nations University Press.

Makiwane, M. (2010) 'The Child Support Grant and teenage childbearing in South Africa', Development Southern Africa. 27(2): 193-204.

McEvan, C. (2005) 'New spaces of citizenship? Rethinking gendered participation and empowerment in South Africa', Political Geography, 24(8): 969-991.

McLachlan, M. \& Hamann, R. (2011) 'Theme issue on food security', Development Southern Africa, 28(4): 429-430.

Mubangizi, B.C. (2008) 'Responses to poverty in postapartheid South Africa: some reflections', International Journal of Social Welfare, 17: 174-181.

Mubangizi, J.C. and Mubangizi, B.C. (2005) 'Poverty, human rights law and socio-economic realities in South Africa', Development Southern Africa, 22(2): 277-90.

Naidoo, K. (2011) 'Poverty and socio-political transition: perceptions in four racially demarcated residential sites in Gauteng', Development Southern Africa, 28(5): 627-39.

Notten, G. \& De Neubourg, C. (2011) 'Monitoring absolute and relative poverty: "not enough" is not the same as "much less"', The Review of Income and Wealth, 57(2): 247-269. 
Okech, D, Howard, W.J., Mauldin, T., Mimura, Y. and Kim, J. (2012) 'The effects of economic pressure on the resilience and strengths of individuals living in extreme poverty', Journal of Poverty, 16(4): 429-446.

Oldewage-Theron, W.H. and Slabbert, T.J.C. (2008) 'Impact of food and nutrition interventions on poverty in an informal settlement in the Vaal Region of South Africa', Proceedings of the Nutrition Society, 67: 91-97.

O'Riordan, T., Nicholson-Cole, S. and Milligen, J. (2008) 'Designing sustainable coastal futures', Twenty-first Century Society. Journal of the Academy of Social Science, 3(2): 145-57.

Pharaoh, R. (2005) 'Aids, orphans and crime. Exploring the linkages' SA Crime Quarterly, 13: 7-14.

Rahaman, M.M. and Varis, O. (2005) 'Integrated water resources management: evolution, prospects and future challenges', Sustainability: Science, Practice, \& Policy, 1(1): 15-21.

Sacks, J. (2008) 'The end of poverty: economic possibilities for our time', European Journal of Dental Education, 12(1): 17-21.

Shisanya, S.O. and Hendriks, S.L. (2011) 'The contribution of community gardens to food security in the Maphephetheni uplands', Development Southern Africa, 28(4):509-526.

Singh, S. (2010) 'The South African 'Information Society', 1994-2008: Problems with policy, legislation, rhetoric and implementation', Journal of Southern African Studies, 36(1): 209-227.

Spira, M. and Wall, J. (2006) 'Issues in multigenerational families: adolescents' perceptions of grandparents' declining health', Child and Adolescent Social Work Journal, 23(4): 390-406. 
Streak, J.C. (2004) 'The GEAR legacy: did GEAR fail or move South Africa forward in development?', Development Southern Africa, 21(2): 271-288.

Tregenna, F. (2012). 'What are the distributional implications of halving poverty in South Africa when growth alone is not enough?', Applied Economics, 44(20): 2577-2596.

Versi, A. (2014) 'The two faces of Africa’ African Business, 409: 16-20.

Vorster, J. and De Waal, L. (2008) 'Beneficiaries of the child support grant: findings from a national survey', Social Work Practitioner-Researcher/ Maatskaplikewerk Navorser-Praktisyn, 20(2): 233-249.

Webb, N.L. (2011) 'When is enough, enough? Advocacy, evidence and criticism in the field of urban agriculture in South Africa', Development Southern Africa, 28(2): 195-208.

Wolf-Powers, L. (2008) 'Expanding planning's public sphere. STREET Magazine, activist planning, and community development in Brooklyn, New York, 1971-1975', Journal of Planning Education and Research. 28: 180-195. 